\title{
DIZERES REVOLTOS: DISCURSO, VERDADE, TECNOLOGIA E POLÍTICA
}

Revolted sayings: discourse, truth, technology and politics

\author{
Luzmara Curcino $^{1}$ \\ Universidade Federal de São Carlos - UFSCar \\ Vanice Sargentini ${ }^{2}$ \\ Universidade Federal da Paraíba - UFPB \\ Universidade Federal de São Carlos - UFSCar
}

\footnotetext{
${ }^{1}$ Doutora em Linguística e Língua Portuguesa pela Universidade Estadual Paulista "Júlio de Mesquita Filho", campus de Araraquara (UNESP/FCLAr), docente no Departamento de Letras e no Programa de Pós-graduação em Linguística da Universidade Federal de São Carlos (UFSCar). Coordenadora do Laboratório de Estudos da Leitura (LIRE/CNPq).

${ }^{2}$ Doutora em Linguística e Língua Portuguesa pela Universidade Estadual Paulista "Júlio de Mesquita Filho", campus de Araraquara (UNESP/FCLAr), docente no Programa de Pós-graduação em Linguística da Universidade Federal de São Carlos (UFSCar), professora visitante do Departamento de Letras e Linguística da Universidade Federal da Paraíba (UFPB). Coordenadora do Laboratório de Estudos do Discurso (Labor/CNPq).

* A parceria na vida e na academia é responsável, entre outras, pela organização das edições do CIAD Colóquio Internacional de Análise do Discurso, e das obras coletivas, Discurso, Semiologia e História (Editora Claraluz, 2011), Presenças de Foucault na Análise do discurso (EdUFSCar, 2014) e (In)Subordinações Contemporâneas: Consensos e resistências nos discursos (EdUFSCar, 2016).
} 
Vivemos em um tempo de mudanças importantes e aceleradas. Essa percepção talvez seja atestável em qualquer período, ainda que não para a totalidade dos sujeitos que nele viveram, afinal, ser contemporâneo não significa vivenciar as mesmas coisas, nem do mesmo modo, nem ao mesmo tempo. Isso porque nossa percepção relaciona-se à partilha de nossa existência e experiências estabelecidas por nossa proveniência, nosso convívio em um tempo e espaço específicos, relacionados aos nossos grupos de origem e pertencimento, nossas formas de convivência, nossas relações sociais organizadas por essa origem e pertencimento bem como pelos encontros fortuitos com o outro, cuja somatória depois nomeamos de nosso destino.

Nossa percepção do mundo, das práticas e dos sujeitos é em grande medida moldada pelos discursos a que somos expostos, aos quais aderimos e recusamos, com os quais convivemos de modo mais aproximado ou distante, e em relação aos quais, e a seu funcionamento de mediador de nossa relação com o mundo, variam os graus de consciência. Assim, o discurso, como instância mediadora de nossa relação com o mundo, com as práticas e com os sujeitos, diz respeito a tudo que em determinado momento histórico e em uma dada sociedade ou, em seu interior, em uma dada comunidade, é dito, reiterado, disposto em uma hierarquia dos dizeres, adquirindo mais ou menos valor distintivo, mais ou menos valor de verdade em relação ao mundo, às práticas e aos sujeitos.

\section{A ordem do discurso em temos de verdade relativizada}

O discurso é uma 'ordem', já disse o filósofo ${ }^{3}$, uma ordem estabelecida no tempo e no espaço. Essa 'ordem' atua como um dispositivo de triagem dos dizeres, de sua organização, distribuição e circulação sistemática, responsável por seu grau de legitimidade em determinado período, segundo uma dada ancoragem cultural e junto a certos sujeitos. Essa 'ordem' também atua como um dispositivo de injunção ao dizer, mas não a qualquer um. Ela, portanto, controla o que se diz, quem pode dizer, assim como institui o poder desses dizeres e dos sujeitos, que são, por sua vez, não apenas autorizados a dizer, mas também instados a enunciá-los segundo uma 'economia discursiva' vigente. Trata-se, portanto, de uma ordem que organiza o que é dizível, à medida que simultaneamente o impõe.

\footnotetext{
${ }^{3}$ Michel Foucault (1996).
} 
Assim, não é tudo que se pode e se deve dizer, nem são todos que podem indistintamente tomar a palavra, sob a pena desse dizer ser desabonado, caso seu enunciador não goze do abono institucional e com isso não se inscreva no 'verdadeiro da época', e não enuncie segundo a 'vontade de verdade' 4 que rege as relações dos sujeitos em determinado tempo-espaço.

É graças às instituições a partir das quais se enuncia, em nome delas, e segundo o que elas reproduzem, que um dado dizer se valida, é mantido, registrado, preservado, ritualizado, de modo a permanecer, e a permanecer como dizer legítimo e verdadeiro. O poder e o 'valor de verdade' do que um sujeito enuncia advém, portanto, de sua adequação ao discurso instituído e institucional, sob os auspícios de uma instituição reconhecida, prestigiada, em diferentes escalas junto a distintos grupos.

Portanto, o valor de verdade do que é enunciado resulta desse funcionamento discursivo, que é histórica, cultural e socialmente regulado. Na análise do que foi enunciado, no passado ou no presente, sob a forma de uma fala íntima e cotidiana ou daquela mais pública e ritualizada, numa interlocução de ordem familiar, comercial, religiosa, jurídica, midiática ou política, é preciso depreender esse funcionamento e suas especificidades, para compreender como esses discursos atuam sobre quem somos, como agimos, como nos julgamos uns aos outros, como tomamos decisões, enfim, como acreditamos ou desconfiamos do que circula socialmente.

É compreendendo esse funcionamento que a invocação ingênua ou perversa de um relativismo sem limites, que graceja entre nós hoje, pode ser contestada. Essa tendência atual de se referir à verdade como algo meramente relativo, não é politicamente emancipadora, nem honesta. Essa visão relativista, simplória ou mal intencionada, anularia a verdade e abriria a porta para um 'vale tudo' e para um 'tudo vale a mesma coisa', em um indisfarçado mecanismo de falso empoderamento democrático. Aliado a outras ideologias capitalistas, esse relativismo na compreensão da verdade promove um subjetivismo simplificador, que consagraria a verdade como resultante única e exclusivamente a pontos de vista individuais, ainda que compartilhados em grupo. A verdade se encontraria, indistintamente, em todo e qualquer ponto de vista e dizer. Essa ideia 'romântica', alienada e alienante, acerca da potência dos indivíduos encontra diferentes versões em diferentes campos. Com as novas

\footnotetext{
${ }^{4}$ Esses dois conceitos encontram-se descritos em Foucault (1996). Ele define a 'vontade de verdade' como uma "maquinaria prodigiosa de produção da exclusão de certos discursos", e com eles de certos sujeitos. Ele ainda aborda as condições históricas necessárias e variáveis para que um discurso seja assumido como verdadeiro. Um dizer verdadeiro pode ser recusado enquanto tal, caso não se encontre inscrito no "verdadeiro da época", ou seja, no dispositivo próprio a uma dada época e cultura a partir do qual o que se enuncia como verdade resulta das disputas de força, da distribuição e organização do poder.
} 
tecnologias digitais de comunicação e de informação, de produção e de circulação de discursos, testemunhamos um uso político parasitário e conveniente, bastante potente porque relativamente inusitado, dos jogos com a 'verdade'.

\section{Pós-verdade e fake news e o papel do 'boca a boca digital'}

É essa versão relativista mal definida e amplamente difundida hoje em dia que se têm nomeado por "pós-verdade". Ela ganha ainda mais visibilidade no campo da política, onde também se popularizou recentemente a circulação de termos como "fake news". São palavras e expressões que há alguns anos ou não existiam ou se existiam não lhes dedicávamos muita atenção. Elas ganharam força sobretudo nos últimos anos em meio a mudanças tecnológicas de monta e sua ampla instrumentalização pelo marketing político.

Com a popularização de uma série de dispositivos e aplicativos de comunicação e de informação capazes de interligar virtualmente os usuários; com a rapidez, a descentralização e a pulverização de meios de produção e de transmissão de textos, houve uma mudança significativa nos hábitos e nas práticas dos sujeitos quanto aos modos de se comunicar e de se informar, assim como da indústria de marketing, comercial ou político, na interlocução com seus consumidores e eleitores potenciais. Outorgou-se aos sujeitos a potencialização da circulação de opinião em uma espécie de empoderamento do antigo 'boca a boca'. Este já era e continua sendo um procedimento eficaz de convencimento e de produção de adesão, dessa vez em uma escala nunca antes experimentada.

O 'boca a boca digital' expandiu tanto a velocidade de sua difusão quanto o raio de seu alcance. $\mathrm{O}$ marketing comercial e político tem explorado intensamente esse recurso. Ele não apenas multiplica as vias de acesso aos interlocutores potenciais como também se apropria do capital simbólico e social dos indivíduos, de modo que as mensagens transmitidas sejam abonadas por aqueles que as transmitem, e gozem assim das relações de confiança que se estabelecem entre os indivíduos.

Além disso, na política, os usuários são interpelados não apenas como eleitores cujo voto está em disputa. Eles são também convocados como apoiadores virtuais, como agentes do processo da propaganda política com a finalidade de obter votos. Cada um, a sua maneira, atua como uma espécie de 'influenciador digital' junto a sua base, a seus grupos de pertencimento e adesão. Usuários de aplicativos, membros de diferentes redes sociais e 
participantes de diferentes grupos de contato, sua mobilização e participação nas campanhas se tornou, assim, estratégia fundamental do marketing político.

\section{A ilusão de empoderamento político no meio digital}

Há uma ampla série de discursos sobre as novas tecnologias, e se hegemonizam popularmente aquelas de viés promocional, eufórico, positivo. Entre outras qualidades e mudanças bem-vindas que se afirma serem próprias da emergência dessas novas tecnologias digitais de comunicação e informação, é frequente a de que temos acesso rápido, fácil e amplo a uma infinidade de informações. É frequente também a afirmação de que podemos nos expressar individualmente, manifestar nossa opinião, dar vazão ao que concebemos e pensamos e da forma como acreditamos ser mais adequada, participarmos efetivamente da produção de conteúdo. Isso, no entanto, não é verdade para a imensa grande maioria.

Se como usuários tivemos acesso a uma ampla rede de acesso, a fluxos de circulação de textos contínuos, constantes, dispersivos, porém, apenas poucos de nós podem se enquadrar nessa categoria daqueles que efetivamente 'dizem' e que efetivamente são 'ouvidos' na cacofonia ruidosa dessa grande arena virtual.

A internet é o reino de consumidores e não de produtores de conteúdo. Nela se é adulado e compensado com a forte impressão de que se estaria participando desse diálogo gigantesco, ininterrupto, onde atuariam diferentes vozes igualitariamente. Há aí um falso empoderamento dos sujeitos: nem todos têm acesso aos meios, e todos os que têm não dispõem das mesmas condições técnicas, tecnológicas e intelectuais para atuar efetivamente no debate. Além disso, a maioria está fadada a 'compartilhar' o que outros, antes dela produziram, e isso o faz. Pode-se produzir, em tese, mas não se o faz. A ilusão da possibilidade cria a ilusão do realizado. Por isso se acredita que o que se recebe sob a forma de uma postagem foi produzido por um de nós, por um igual, ou no máximo por outros mais dotados ou instrumentalizados para se expressar mais habilmente em relação àquilo que sabemos, acreditamos e defendemos. Duplo engano.

Em tempos de fábricas de fake news, de produção industrial de mentiras políticas, de abuso da boa-fé e do alheamento político da maioria de nós, essa impressão de que atuamos efetivamente na política, por meio de nossas ações no campo virtual, é um grande engodo. A produção dessas notícias que alimentaram o debate político no Brasil nos últimos 5 anos, que afetaram decisivamente os acontecimentos políticos drásticos, que venceram eleições, não se 
encontra na casa dos indivíduos, não partem de postagens em celulares de cada um, como resultantes de sua ação deliberada como formador de opinião na rede virtual. As empresas virtuais de produção de conteúdo e de disseminação acuradamente segmentada desse conteúdo estão na origem do que dizer, fornecendo o que circulará no 'boca a boca digital', o que fundamentará não apenas nosso saber, nossas convicções como também aquilo pelo que lutar, defender, difundir, aquilo pelo que atuaremos como fiadores em nossas redes sociais. Assim, nosso papel nessa cadeia é o de ecoar o que nos é fornecido, alimentando a linguagem cacofônica das redes, segundo a qual se convence pela repetição e se vence pela hegemonia do dizer que circula.

Nas últimas eleições, em especial na estadunidense e na brasileira, esse sistema técnico e discursivo foi mobilizado como nunca e fez um apelo operacional e banalizado da mentira em larga escala ${ }^{5}$. Contando com a certeza de impunidade imediata, da falta de legislação competente ${ }^{6}$ e da expectativa de uma recepção desavisada e suscetível ${ }^{7}$, candidatos aos postos políticos de todos os níveis foram eleitos graças a esses usos 'inéditos' quanto ao tipo de textos formulados e à frequência e facilidade de sua disseminação.

Essa indústria inusitada de informações falsas encontrou solo fértil junto a uma população em sua maioria órfã de políticas de Estado, descrente quanto às chances de mudança de suas condições de vida, revoltada com 'tudo isso que está aí', sem no entanto conhecer as causas de sua miséria, ou o referente preciso desse 'tudo isso que está aí', sem poder atentar criticamente para as verdadeiras motivações daqueles que bradavam estar na contramão e no combate de 'tudo isso que está aí'. Sem pudor quanto ao processo de estelionato eleitoral em curso, o uso intenso e sistemático da 'mentira' como estratégia política viu-se renovado em seus meios e estratégias. Aliada a outras estratégias, a disseminação de notícias falsas fomentou diferentes versões de golpes (alguns bem sucedidos outros nem tanto) no mundo, e especialmente na América Latina. Elas também contribuíram para eleger presidentes de diferentes nações, entre elas a do Brasil.

No cenário caricatural e novelesco da política brasileira dos últimos 5 anos testemunhamos estupefatos, na mídia e nas ruas, capítulos sucessivos e grotescos da escalada da antidemocracia na democracia. Promovida segundo a lógica do 'espetáculo’ próprio das

\footnotetext{
${ }^{5}$ A maioria da população brasileira dispõe de telefone celular e $99 \%$ desses usuários faz uso do aplicativo WhatsApp, amplamente utilizado nestas eleições e pelo atual governo em sua comunicação oficial e extraoficial.

${ }^{6}$ Um ano após as eleições, conforme notícia publicada no portal UOL, em 19 de setembro de 2019, "A rede de fake news com robôs pró-Bolsonaro mantém $80 \%$ das contas ativas", segundo dados obtidos por dois coletivos de ativistas digitais e checados pelos jornalistas responsáveis pela matéria, Eduardo Militão e Aiuri Rebello.

${ }^{7}$ Notícia assinada por Patrícia Pasquini, publicada no jornal Folha de São Paulo, logo após as eleições presidenciais, em 2 de novembro de 2018, afirma que " $90 \%$ dos eleitores de Bolsonaro acreditaram em fake news", conforme estudo realizado pela Avaaz.
} 
mídias massivas, tradicionais ou emergentes, fomos expostos a uma enxurrada de 'escândalos' estruturados para manter nossa atenção e tensão em alta, para nos distrair e dispersar, cujos clímax vão desde a destituição da primeira mulher eleita, de forma legítima e democrática, à presidência de nosso país, passando pela prisão, em tempo recorde da justiça brasileira, com base em interpretações inéditas da legislação brasileira, sem que se tenha esgotado todos os recursos em todas as instâncias de direito, de um ex-presidente que terminou seu mandato com altos e inusitados índices de aprovação de seu governo, e que, embora preso, era o favorito nas pesquisas de intenção de voto das eleições de 2018.

Na sequência desses capítulos políticos dramáticos, como resultado direto do golpe e a cada dia como prova das verdadeiras razões para o golpe, testemunhamos uma novela diária de perda de direitos sociais e políticos duramente conquistados, como aqueles relativos à CLT - Consolidação das Leis Trabalhistas, e isso tudo administrado por um governo ilegítimo e com os menores índices de aprovação da história. Testemunhamos o assassinato de uma liderança política, Marielle Franco, até hoje sem a identificação de todos os suspeitos e culpados e sem sua devida punição. Testemunhamos ainda a entrega irresponsável e tenebrosa de estatais e de direitos de exploração de nossas reservas naturais para grupos privados multinacionais, tudo isso feito, julgado e rifado com uma velocidade impressionante e inusitada no Brasil, sob a batuta da mídia nativa, de nossas elites financistas e políticas, do aparelho judiciário, com a participação de parte de nossa população aturdida, confundida, ludibriada e incitada emocionalmente.

Testemunhamos o crescimento da visibilidade, difícil de digerir, de candidatos que exploraram irresponsavelmente, como plataforma política, as emoções e atitudes humanas mais basilares e intensas, e o fizeram com finalidades para lá de escusas. Instrumentalizaram sistematicamente o medo, o ódio, o ressentimento, a intolerância, o fanatismo, a descrença, o falso moralismo, o desânimo e a violência. Testemunhamos a ladainha da demonização do Estado, infinitamente repetida nos editoriais de nossos jornais, e simultaneamente o endeusamento do 'deus mercado' e da empresa privada ${ }^{8}$, sob rótulos 'bonitos' e repetidos a esmo do 'livre mercado', da 'livre iniciativa', do 'empreendedorismo'. Testemunhamos a grande fogueira de nossa memória, ao vermos o principal museu de nosso país, o Museu Nacional do Rio de Janeiro, arder, depois de sucessivos, irresponsáveis e criminosos cortes de recursos destinados a sua manutenção, de descaso deliberado com a coisa pública. O preço de um golpe se paga assim... com o caos como método.

\footnotetext{
${ }^{8}$ Cf. Souza (2015).
} 
O preço do golpe também se paga com a ressaca, com a indigestão de tudo que não foi possível mastigar, deglutir e processar, e cujo resultado imediato foi a eleição à presidência do país de um político inexpressivo, insignificante, advindo do baixo-clero da política, que ao longo de quase três décadas como congressista passou a maior parte do tempo despercebido, na penumbra cinza dos partidos nanicos que parasitam e compõem o dito 'centrão' do legislativo brasileiro. Esse ex-militar de baixa patente, saudoso do período ditatorial e de seus métodos mais escusos de exercício autoritário do poder, fã declarado de torturadores que atuaram sob os auspícios desse regime e que nunca foram punidos como deveriam graças a uma anistia ampla e irrestrita de que foram os maiores beneficiados, deitou e rolou no 'clima' de desmonte midiático da política, de instrumentalização inescrupulosa da justiça e graças ao apoio internacional, ainda sob o tapete, ao golpe de estado e à sua eleição. Ele também foi beneficiado pelo uso estratégico, sistemático e despudorado de informações falsas replicadas na velocidade dos clicks, graças a aplicativos e aparelhos digitais amplamente popularizados no Brasil, sob os quais não se exerceu nenhum controle ético, não se exigiu nenhuma responsabilidade.

Essa novela, infelizmente, é uma reprise. Nosso futuro promissor, tantas vezes aventado e festejado em alegorias mil, parece estar fadado a ser frequentemente interrompido ou protelado por uma sucessão de golpes conservadores, que posam de remédio amargo tão facilmente administrado por nossa elite sobre a nação.

Diante desse cenário, que visa a todo custo aquebrantar essa nossa estranha e talvez romântica esperança nesse futuro sempre esperado, diante desse cenário que visa dobrar, submeter, diminuir nossa capacidade conjunta de resistir e de perseverar contra esse desmonte sistemático de conquistas e lutas coletivas, o que deve nos fortalecer, animar e alegrar é o sentimento de não estarmos sozinhos na luta e a certeza de que ela compensa, em nome do presente e do futuro da maioria de nós destituída até mesmo dos direitos mais básicos, de moradia, de alimentação, de educação, de saúde, de segurança e de justiça.

Luta que se encampa no dia a dia de nossa atuação docente, de nossas pesquisas, e da reflexão conjunta como as realizadas em atividades e eventos, como os que originaram a proposição deste número temático da Revista Heterotópica, dedicado à reflexão sobre os Diálogos transversais: discurso, política e verdade, em especial em um tempo em que a política e a disputa por votos se vale tanto de diferentes e inusitados recursos técnicos de enunciação em redes sociais quanto da flexibilidade ética que vimos ser exercida nesse meio, impulsionada pela lógica das 'verdades alternativas', das 'fake news' e da 'desinformação'. 
Nesta edição temática da revista Heterotópica nos propusemos a abordar a relação intrincada e fundamental entre 'discurso', 'política' e 'verdade'. Para tal, publicamos aqui especialmente uma série de entrevistas com intelectuais de diferentes campos - da linguística, da sociologia, da psicanálise e da história - que se dispuseram a fazer um breve panorama de suas pesquisas e a partir delas refletir sobre essa temática, além de um artigo que trata da produção de verdades pelo campo midiático.

As entrevistas foram realizadas como atividade da disciplina Laboratório 6 - Textos: Meios e Materiais Instrucionais, por discentes do curso de Bacharelado em Linguística da UFSCar - Universidade Federal de São Carlos, sob a supervisão da docente Luzmara Curcino, na ocasião do V CIAD - V Colóquio Internacional de Análise do Discurso, entre os dias 12 a 14 de setembro de 2018, nesta mesma universidade. Este evento foi organizado pelos grupos de pesquisa LABOR - Laboratório de Estudos do Discurso e LIRE Laboratório de Estudos da Leitura, coordenados respectivamente pelos docentes Vanice Sargentini, Carlos Piovezani e Luzmara Curcino, que atuam no Departamento de Letras e no Programa de Pós-graduação em Linguística da UFSCar. Com o tema Discurso $\boldsymbol{e}$ (pós)verdade: efeitos de real e sentidos da convicção ${ }^{9}$, a $5^{\text {a }}$ edição do CIAD foi dedicada a refletir sobre as relações entre discurso e verdade, tendo em vista as mudanças presenciadas no cenário atual, em especial na conjuntura política nacional e internacional em que diversos acontecimentos exigem, para sua compreensão, a consideração acurada das novas formas de produção, formulação e circulação de discursos estabelecidas sob a égide da cultura digital. Uma das diferenças promovidas com a emergência e expansão de técnicas e tecnologias virtuais, quanto aos discursos, recai sobre as condições de validação do dizer, sobre sua condição de dizer fiável, verdadeiro.

Nessas entrevistas, travamos contato com diferentes contribuições de diferentes áreas de saber acerca do discurso e sua relação com a constituição dos poderes, mas também das resistências a esses poderes, do discurso e sua relação com a produção dos consensos, mas também com sua força de fazer emergir os dissensos, do discurso e sua relação com a construção da verdade, mas também com as formas que questionam, avaliam e denunciam os mecanismos de produção de um dizer que se quer verdadeiro, que se impõe como tal, e que pela força de sua circulação e institucionalização silencia outros dizeres e naturaliza sua condição hierárquica e muitas vezes autoritária.

\footnotetext{
${ }^{9}$ Informações sobre os palestrantes do V CIAD, bem como acesso aos vídeos das conferências e mesas-redondas dos convidados nacionais e internacionais encontram-se disponíveis no site <http://www.ciad.ufscar.br/>.
} 
Com essas reflexões aqui expressas, se pode constatar como a verdade se liga intrinsicamente ao discurso, porque ela é um de seus resultados, de suas consequências. $\mathrm{O}$ valor de verdade do que enunciamos depende, não apenas do que haveria de essencial no que se diz, mas de disputas (em sua maioria desiguais), de uma vontade de verdade de certos grupos, e da força e do poder de distribuir, de institucionalizar, de durar no tempo e de naturalizar essa 'vontade de verdade' como a 'verdade', mesmo ao preço da distorção do real, de sua corrupção, de sua inversão.

Convencidos de que as diversas relações entre discurso, verdade e política podem tanto libertar quanto assujeitar, que elas podem se inscrever em posições conservadoras e ensejar discursos reacionários e até fascistas, mas podem igualmente derivar de posicionamentos progressistas e produzir pensamentos, atos e palavras emancipatórios, que como intelectuais, professores e pesquisadores, nossas ações, como a de reflexão e publicação de seus resultados, podem fazer pender a balança para essa finalidade emancipatória, quando analisamos o modo de funcionamento da produção dos discursos e de sua circulação, quando demonstramos sua distribuição regrada, quando expomos as razões de sua duração distinta, quando denunciamos, enfim, as formas de hierarquização naturalizadas e a quem elas servem.

\section{Sobre as entrevistas}

Na primeira entrevista, intitulada Psicanálise, Política e Verdade, o psicanalista e professor Tales Ab'Sáber reflete sobre a disputa pela 'verdade' histórica e as formas como diferentes sujeitos e para diferentes fins dela se apropriam, mobilizando-a para fins políticos eleitorais. Inicialmente, aborda um desses usos, discutindo o revisionismo histórico e de sua relação com o fascismo. Em seguida, apresenta as contribuições que campos científicos e reflexivos como a Psicanálise podem fornecer para lidarmos com o atual contexto político brasileiro, em que o revisionismo e o fascismo gracejam no modus-operandi da extremadireita antidemocrática, violenta, que põe em marcha um discurso de ódio.

$\mathrm{Na}$ segunda entrevista, intitulada Mulheres em discurso: linguagem, política e verdade, realizada com a professora e linguista Mónica Zoppi Fontana, além de nos apresentar seu grupo de pesquisas "Mulheres em Discurso", que tem por objetivo fomentar a reflexão sobre os processos de subjetivação da mulher, em nossa sociedade, por meio dos discursos e das práticas engendradas a partir deles, a pesquisadora trata da pós-verdade, cenário no qual prevalecem afirmações de viés prioritariamente emotivo, do campo das 
crenças e das ideologias pessoais, diferentemente das afirmações que buscam se ancorar na maior aproximação dos fatos.

O historiador francês, Roger Chartier, na terceira entrevista, intitulada História do livro e da leitura e a 'verdade' na História, nos apresenta reflexões acerca de duas das principais frentes de seu trabalho de pesquisa: um breve panorama da História da cultura escrita no Ocidente, a partir da relação entre as mudanças ocorridas na forma material do livro e as mudanças nas práticas de escrita e de leitura e o impacto da emergência das novas tecnologias digitais de produção escrita e editorial dos textos e de sua recepção; e suas reflexões quanto à especificidade da História, enquanto disciplina, e o valor de verdade de suas narrativas.

Já o linguista e professor Sírio Possenti, em sua entrevista, intitulada Estudos linguísticos, Humor, Política e Ensino de Língua, aborda alguns dos temas a que se dedica, nos apresentando as contribuições que outros campos de estudo trouxeram para os estudos linguísticos, como aquelas provenientes da Filosofia. Ele também trata das relações entre o humor, a mídia e a política, de uma perspectiva discursiva, e finaliza discutindo a importância dos conhecimentos científicos sobre a língua e a linguagem para o ensino de língua portuguesa no Brasil.

A professora e pesquisadora no campo dos estudos discursivos, Maria Aldina Marques, em sua entrevista, O Discurso político e a polidez: um fenômeno da gentileza ou da agressão?, permeou alguns tópicos relacionados a sua pesquisa, tendo como ponto de partida a definição e explicação do seu objeto de pesquisa de maior interesse: o discurso político parlamentar. Para tal, explicita o uso distinto das expressões e/ou palavras prototípicas de um discurso político que podem vir a gerar efeitos de polidez, gentileza ou agressão. Além das expressões prototípicas, aborda também a questão das distinções entre o discurso político europeu e o discurso político brasileiro, focalizando os pronomes de tratamentos utilizados em cada um deles. A seguir, a entrevistada fala a respeito da aplicação desses mecanismos linguísticos no ensino básico e aprendizado. Ao final, Marques traz à luz o processo de execução de uma de suas obras intitulada Política e humor: divertir para melhor comunicar, que diz respeito à espetacularização e midiatização da política. Por fim, a linguista faz uma correlação entre discurso e verdade em conformidade com o tema do Colóquio, e assinala contrapontos em relação à objetividade e à subjetividade do discurso.

Em seguida, na entrevista intitulada Língua(gens), mídia(s) e poder sob a ótica discursiva foucaultiana, a pesquisadora e professora Maria do Rosário Gregolin discorre sobre as contribuições da Análise do Discurso foucaultiana para o ensino da língua e para a produção e circulação de textos na atualidade. A linguista nos lembra que a língua pode 
funcionar como um instrumento de poder, porque por ela tanto se pode oprimir quanto se emancipar. Ademais, discute a relevância das leituras foucaultianas para a constituição da Análise do Discurso (AD) no Brasil, e em sua esteira aborda em seus estudos diferentes dispositivos que atuam no controle de nossas práticas e na produção de nossas identidades. Entre eles, ela tem se dedicado às novas mídias digitais, seus usos e seus impactos na atualidade, responsáveis por uma maior produção e difusão de conteúdos adulterados, com a banalização das chamadas fake news, o que nos impõe o necessário debate sobre esses dispositivos discursivos e seu papel na construção da(s) verdade(s).

Em seguida, o cientista social e especialista em política internacional Jean-Jacques Kourliandsky, em sua entrevista Mudanças políticas e eleições na América Latina, avalia o cenário político atual dessa região e afirma que, embora na grande maioria dos países latinoamericanos, nas últimas décadas, a democracia tenha demonstrado um funcionamento adequado através da conquista dos direitos eleitorais, se observa atualmente um refluxo quanto a esses direitos e ganha força ideias conservadoras e de extrema-direita, que flertam com o autoritarismo. O pesquisador também relaciona a esse refluxo político a propagação e circulação de inverdades.

A professora e pesquisadora Elvira Arnoux, estudiosa de discursos sobre a língua, em especial sobre a glotopolítica e as diferenças e desigualdades linguísticas, em sua entrevista intitulada $\mathbf{O}$ contexto sociopolítico de integração sul-americana: uma visão linguística, aborda, de uma perspectiva discursiva, o contexto sociopolítico de integração sul-americana, apresentando uma análise das práticas linguísticas e dos lugares enunciativos, com base no funcionamento de uma dada memória discursiva sobre a(s) língua(s), que delimita(m) os processos históricos de formação de identidade dos sujeitos latino-americanos.

Em sua entrevista Gênero e Política no Brasil e na Alemanha, a analista de discursos Dinah Leschzyk apresenta um panorama de suas pesquisas sobre o discurso político na América Latina. Ela inicia tratando das especificidades da campanha política na Colômbia, sobre a qual desenvolveu sua tese de doutorado, e nos apresenta sua pesquisa mais recente, relativa ao impacto do gênero na política. Ela tem realizado análises comparativas de discursos que circulam na mídia e nas campanhas eleitorais sobre as duas mulheres presidentes, Angela Merkel e Dilma Rousseff, assim como sobre os discursos de ódio proferidos contra a comunidade LGBT pelas extremas-direitas alemã e brasileira, para os quais o emprego sistemático da mentira é fundamental.

Por fim, o cientista social e especialista em análise de discurso político Mariano Dagatti, em sua entrevista intitulada Discurso Político, Mídia e Verdade, aborda suas 
pesquisas sobre os estilos de comunicação política adotados pelos três últimos presidentes eleitos na Argentina, Néstor Kirchner (de 2003 à 2007), Cristina Fernández (de 2007 a 2015), e Mauricio Macri (de 2015 a 2019). Ele também reflete sobre a relação entre os meios e as instituições de comunicação novos e tradicionais, suas semelhanças e diferenças e sua relação com a política, com a verdade e com o ensino.

\section{Sobre o artigo}

Em artigo intitulado Discursos e regimes de verdade em enunciados sobre o sujeito quilombola na mídia, Claudemir Sousa analisa, em textos publicados pelo jornal $O$ Estado do Maranhão, os regimes de verdade que sustentam a produção enunciativa sobre o sujeito quilombola. Ancorado na perspectiva dos Estudos Discursivos Foucaultianos, o autor fundamenta sua reflexão na dimensão histórica dos discursos, e observa que "os discursos da mídia acerca do sujeito quilombola na história de construção da sociedade brasileira elaboram regimes de verdade" que se pautam na sua relação com a política, seja "no acontecimento da assinatura da Lei Áurea, em 13 de maio de 1888", seja "nas lutas pela liberdade dos escravizados travadas por Zumbi dos Palmares, morto em 20 de novembro de 1695 ".

Esperamos que a leitura desses textos e as reflexões neles promovidas sejam mais um dos gestos de resistência intelectual tão necessários em tempos de dizeres revoltos!

\section{Referências}

FOUCAULT, Michel. A ordem do discurso: aula inaugural no Collège de France, pronunciada em 02 de dezembro de 1970. São Paulo: Edições Loyola, 1996.

SOUZA, Jessé. A tolice da inteligência brasileira: ou como o país se deixa manipular pela elite. São Paulo: LeYa, 2015. 